\title{
The Investigate Metallurgical Properties of Roll Bonding Titanium Clad Steel
}

\author{
Mohsen Saboktakin, Gholam Reza Razavi, and Hossein Monajati
}

\begin{abstract}
Cladding of steel with titanium alloys is used widely in aerospace, chemical and nuclear industries, to improve corrosion behavior and reduce production costs. Roll bonding is one of the solid state processes to produce this combination. In this research the high quality bonding of hot roll bonding of titanium on steel substrate was investigated in terms of metallurgical and mechanical properties. The effect of copper interlayer on preventing inter-diffusion was also evaluated. The microstructure at interface was observed by an optical and scanning electron microscope and the presence of intermetallic phases in the reaction zone was examined by $X$-ray diffraction on the fracture surfaces of the joints. The experimental results showed that the volume fraction of intermetallics may be controlled effectively using cupper interlayer, because there is not enough time for interdiffusion of the elements. Total thickness of intermetallic layers and microhardness at the interface increased with increasing bonding temperature.
\end{abstract}

Index Terms-Hot roll bonding, titanium, clad, metallurgical properties.

\section{INTRODUCTION}

Titanium cladding of steel offers unique characteristic of corrosion resistance which results in extensive application of this metallic composite in nuclear, chemical, aerospace, oil and gas and petrochemical industries [1], [2]. The most important challenge to be overcome in titanium cladding is obtaining an interface with an acceptable bonding strength. Titanium possesses limited solubility in iron. Additionally, it is a strong carbide forming element capable of forming brittle compound of $\mathrm{TiC}$ and $\mathrm{Fe}-\mathrm{Ti}$ intermetallic compounds in contact with steel which decreases the strength of interface bonding[3]. Formation of $\mathrm{TiC}$ is a diffusion based phenomenon which requires adequate time to accomplish. Therefore, processes such as explosive welding with very short process time can yield no brittle compound[3]. However, it is known that the explosive welding has many limitations, for example dimensions of plates to be welded are limited and the process and is expensive. In addition, huge residual stress and plastic deformation in the interface leads to stress corrosion cracking in the interface so that heat treating of the interface is inevitable to relax the stresses [3]. Diffusion bonding on the other hand, with long time required to complete the process, needs special considerations such as utilizing suitable interlayer to inhibit diffusion and avoid

Manuscript received October 4, 2011; revised November 10, 2011.

M. Saboktakin, G. R. Razavi, and H. Monajati are with Department of Materials Science and Engineering, Najafabad Branch, Islamic Azad University, Isfahan, Iran (e-mail: Mohsen.Saboktakin@Gmail.com; Reza.Razavi64@Gmail.com; Monajati@Gmail.com). degradation of bonding interface. Formation of the brittle $\mathrm{Fe}-\mathrm{Ti}$ intermetallics at interface, make it prone to create discontinuities and crevices, so it is easy to damage prematurely in corrosive environment.

Roll cladding with a medium time to reach the required temperature for rolling, satisfactory rate of production and superior capability of automation has attracted more attention. In roll cladding, the difference between coefficients of linear expansion of the two sheets can lead to considerable stress development which should be relieved via heat treatment. Application of a copper interlayer can prevent formation of brittle intermetallic compounds of Fe-Ti [4], [5]. According to the phase diagram of $\mathrm{Fe}-\mathrm{Cu}$, these elements do not form intermetallic compounds and also compounds between copper and titanium are not very brittle [6]. Furthermore, a relatively low melting point of copper and its high plasticity makes it an appropriate choice.

In the present investigation, roll cladding of commercially pure (CP) titanium on plain carbon steel with a copper interlayer were performed and the resulted properties of interface were evaluated.

\section{EXPERIMENTAL}

$\mathrm{CP}$ titanium and plain carbon steel sheets $150 \times 100 \times 2 \mathrm{~mm}$ in dimensions with the compositions shown in the table 1 were used together with $\mathrm{CP}$ copper foil as the interlayer.

TABLE I: CHEMICAL COMPOSITIONS OF THE BASE METALS.

\begin{tabular}{cccccccccc}
\hline & $\mathrm{C}$ & $\mathrm{Ti}$ & $\mathrm{Mn}$ & $\mathrm{H}$ & $\mathrm{O}$ & $\mathrm{N}$ & $\mathrm{P}$ & $\mathrm{S}$ & $\mathrm{Fe}$ \\
\hline $\mathrm{Ti}$ & 0.02 & $\mathrm{Bal}$ & & 0.01 & 0.25 & 0.03 & - & - & 0.03 \\
\hline Steel & 0.12 & & 0.05 & & & & 0.05 & 0.6 & Bal. \\
\hline
\end{tabular}

The sheets were fixed together and put in a furnace with neutral atmosphere in the temperature range of $800-900^{\circ} \mathrm{C}$. Preheating were prolonged for 40 minutes and then the sandwiches were subjected to hot rolling to reach to a true strain of $30 \%$, and eventually located in a furnace of neutral atmosphere to cool down gradually.

Microstructural features of the hot rolled sandwiches were characterized using optical microscope and scanning electron microscope (SEM). Nital 3\% and Kroll's reagent were used respectively to etch the steel and titanium sections of the sandwich. Compositional analysis of the compound was performed by EDX equipment on the SEM. The Jefrees' linear method was used to measure the grain size of the specimens. To determine the different phases in the matrix of steel and titanium after bonding, a X-ray diffractometer of Philip X'Pert model was employed.

The strength of the bonding between layers was determined via peeling test according to ASTM standard 
D1876 using a tensile test machine of Instron 4486. A micro hardness tester with Vickers indenter and a load of $37.63 \mathrm{~g}$ was employed to assess the mechanical strength of the cladding, interface and sub layer at room temperature. Micro hardness measurement was performed at distances of 25,50 , 100 and $200 \mu \mathrm{m}$ surrounding the interface in order to depict hardness profile.

\section{RESULTS AND DISCUSSION}

The experimental results showed that the Titanium cladding on steel via hot rolling with the rolling mill machine in the preheating temperature range of $800-900^{\circ} \mathrm{C}$ was applicable. That was because of the hexagonal crystal structure of the $\alpha$-titanium that possesses limited slip systems. Therefore, there is high resistance to plastic deformation which is essential in tearing away oxide film of titanium and exposing virgin metal surfaces to the copper foil; a fact that is crucial for achievement of metallurgical bonding and is due to the high reduction in thickness during rolling process. Rolling temperature lower than $800^{\circ} \mathrm{C}$ is not sufficient for the formation of bonds considering the capability of the rolling mill. On the other hand, titanium and copper form eutectic composition at temperatures beyond $900^{\circ} \mathrm{C}$ that increases intermetallic compounds along titanium copper interface resulting in cracking and separation in interface of the cladding and substrate [6].

Optical micrographs of the Cross-section of the titanium/copper/steel interface and the grain size of the parent metals at temperatures of 800,850 and $900^{\circ} \mathrm{C}$ are shown in Fig. 1. It can be seen that increasing preheating temperature leads to increasing the grain size of both titanium and steel substrates.

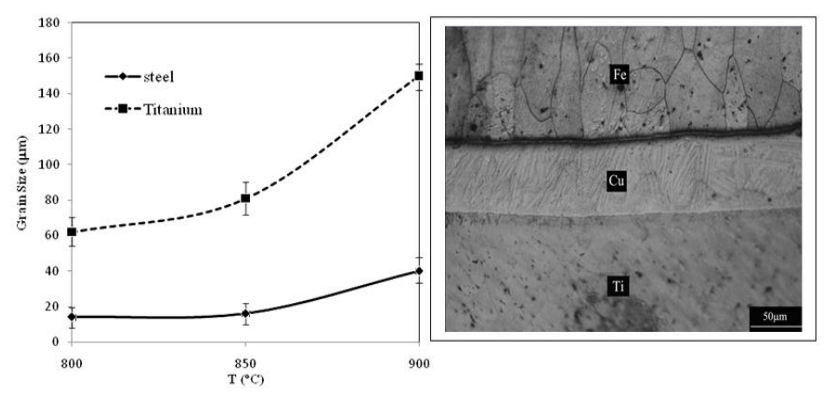

Fig. 1. Optical micrographs of the Cross-section of the titanium-copper-steel interface and the grain size of the parent metals for the samples joined at temperatures of 800,850 and $900^{\circ} \mathrm{C}$.

Fig. 2 show the SEM image of $\mathrm{Fe}-\mathrm{Cu}$ interface of roll bonded joints with a rolling reduction of $30 \%$ at bonding temperature of $900{ }^{\circ} \mathrm{C}$. According to the figure, there is no obvious reaction or diffusion layer at the $\mathrm{Fe}-\mathrm{Cu}$ interface. The extent of diffusion between iron and copper is limited [7].

Fig. 3 shows the SEM images of $\mathrm{Ti}-\mathrm{Cu}$ interface at bonding temperatures of $800,850,900^{\circ} \mathrm{C}$. Distribution profile of the elements at bonding temperature of $900^{\circ} \mathrm{C}$ through the interface is also shown. It can be seen from Fig. 3 that three transition layers have formed at $\mathrm{Cu}$-Ti interface the thickness of which varies with chemical composition, the probable phase and the bonding temperature. Thicknesses of the three layers are shown in Table 3, together with probable phases in each layer determined by EDX and Ti-Cu binary phase diagram. The intermetallics of $\mathrm{TiCu}_{4}, \mathrm{Ti}_{2} \mathrm{Cu}_{3}, \mathrm{Ti}_{3} \mathrm{Cu}_{4}$, $\mathrm{TiCu}$ and $\mathrm{Ti}_{2} \mathrm{Cu}$ and their mixture are formed in the transition layers [8].

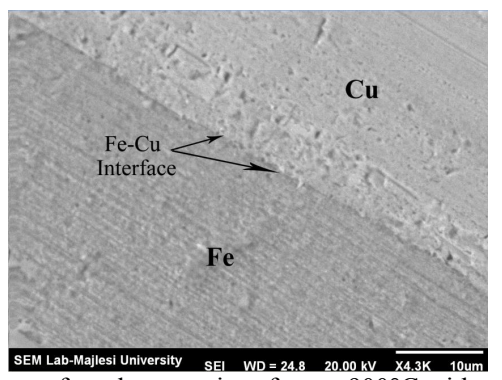

Fig. 2. SEM image of steel-copper interface at $900^{\circ} \mathrm{C}$ with rolling reduction of $30 \%$.

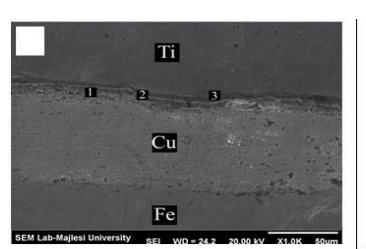

(a)

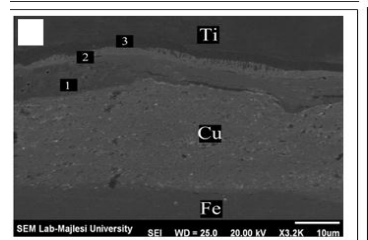

(c)

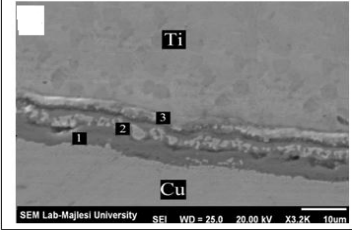

(b)

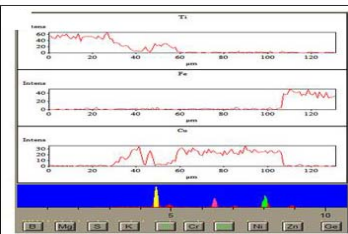

(d)
Fig. 3. SEM images of Ti-Cu interface at bonding temperatures of a) 800 , b) 850, c) $900^{\circ} \mathrm{C}$ and element distribution profile of the interface of $\mathrm{Ti}-\mathrm{Cu}$ bonded at the bonding temperature of $900^{\circ} \mathrm{C}$.

The total thickness of the intermetallic layers at the $\mathrm{Cu}-\mathrm{Ti}$ interface increases with bonding temperature due to increasing of diffusion distance of $\mathrm{Cu}$ and Ti. Moreover, above $882^{\circ} \mathrm{C}$, Ti crystal structure transforms from $\alpha(\mathrm{HCP})$ to $\beta(B C C)$ with a lower packing factor more suitable for copper atoms to diffuse through the lattice [9].

TABLE II: CHEMICAL COMPOSITION, PROBABLE PHASE AND THICKNESS OF INTERMETALLIC LAYERS BETWEEN CU AND TI

\begin{tabular}{|c|c|c|c|}
\hline $\begin{array}{c}\mathrm{T} \\
\left({ }^{\circ} \mathrm{C}\right)\end{array}$ & $\begin{array}{c}\text { Intermetallic } \\
\text { layer }\end{array}$ & Probable phase & Thickness ( $\mathrm{m})$ \\
\hline \multirow{3}{*}{800} & 1 & $\mathrm{Ti}_{2} \mathrm{Cu}_{3}+\mathrm{TiCu}_{4}$ & $2.6-3.7$ \\
\hline & 2 & $\mathrm{TiCu}+\mathrm{Ti}_{3} \mathrm{Cu}_{4}$ & $1-1.7$ \\
\hline & 3 & $\mathrm{Ti}_{2} \mathrm{Cu}+\mathrm{Ti}$ & $2-4.7$ \\
\hline \multirow{3}{*}{850} & 1 & $\mathrm{Cu}+\mathrm{TiCu}_{4}$ & $4.5-6$ \\
\hline & 2 & $\mathrm{Ti}_{2} \mathrm{Cu}$ & $2-3$ \\
\hline & 3 & $\mathrm{TiCu}+\mathrm{Ti}_{2} \mathrm{Cu}$ & $2-3$ \\
\hline \multirow{3}{*}{900} & 1 & $\mathrm{Ti}_{2} \mathrm{Cu}_{3}+\mathrm{Ti}_{3} \mathrm{Cu}_{4}$ & $17-42$ \\
\hline & 2 & $\mathrm{Ti}_{2} \mathrm{Cu}+\mathrm{TiCu}$ & $7-11$ \\
\hline & 3 & $\mathrm{Ti}_{2} \mathrm{Cu}+\mathrm{Ti}$ & $10.5-13.5$ \\
\hline
\end{tabular}

$\mathrm{Cu}-\mathrm{Ti}$ interface is characterized by the presence of the Widmanstatten $\alpha-\beta$ titanium structure. Copper is a strong $\beta$-stabiliser element. Migration of copper atom to titanium lattice lowers the eutectoid transformation temperature of titanium and $\alpha-\beta$ phase structure forms owing to decomposition of $\beta$-Ti during cooling [10-11]. This structure 
is shown in Fig. 4.

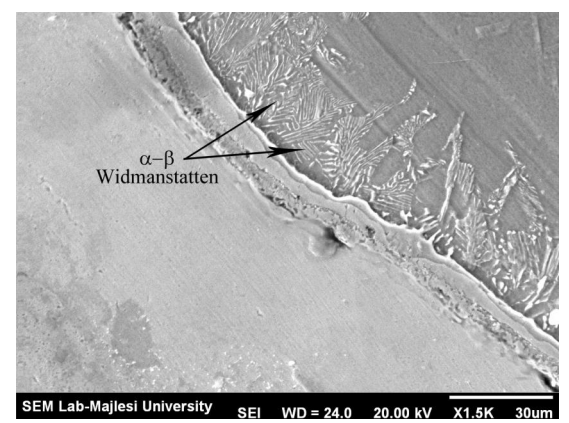

Fig. 4. SEM images of the Widmanstatten $\alpha-\beta$ titanium structure formed at $\mathrm{Ti}-\mathrm{Cu}$ interface.

The peel strength of the hot roll bonded joints at different bonding temperature are depicted in Fig. 5.
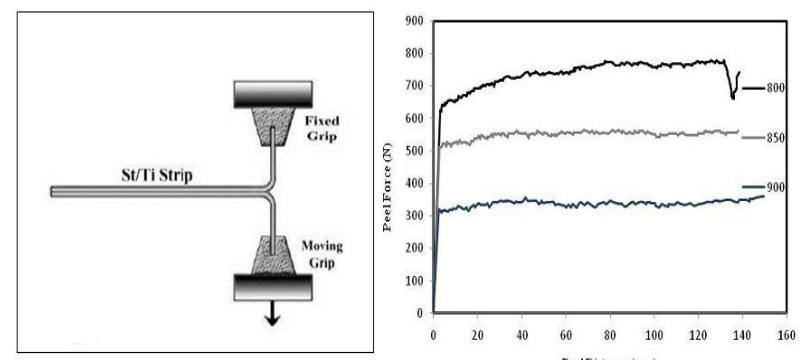

Fig. 5. Schematic illustration of peeling test and variation of the peeling force in as-received roll bonded strips at different temperatures.

The average peel strength was determined using the following equation:

$$
\text { Average Peel Strength }=(\text { Average Load } / \text { Bond Width })
$$

As it may be seen from the figure, the peel strength of the roll bonded joints decrease with increasing bonding temperature. This may be attributed to increase in the total thickness of intermetallic layers and the resulted brittleness of bonded joints.

The results of the micro hardness measurements together with an optical micrograph of the measurement region near the interface are presented in Figure $6 a$ and $b$, respectively. First of it is clear that the hardness in all areas increases with increasing rolling temperature. This was assessed by measuring the interface thickness and it was observed that higher temperature leads to thicker interface layer. As microhardness in such thin layer may be affected by neighbor layers, therefore, hardness can be increased by increasing thickness. It is also well recognized that titanium side has a higher hardness than steel side. However, the difference is more evidenced in two $50 \mu \mathrm{m}$ band on opposite sides of the interface. The higher hardness of interface band on titanium side may be attributed to the intermetallic compounds formed between Ti- $\mathrm{Cu}$ [4], [12] as well as widmanstuten $\alpha-\beta$ microstructure. However, from the element distribution diagram in Figure 3 it is observed that there is no long diffusion of $\mathrm{Cu}$ atoms into the Fe lattice and higher hardness in the interface band on steel side cannot be due to intermetallic compounds. This may be attributed to higher density of dislocation and metal work hardening near interface.

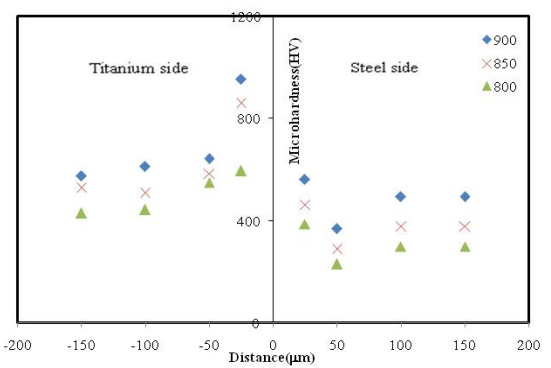

(a)

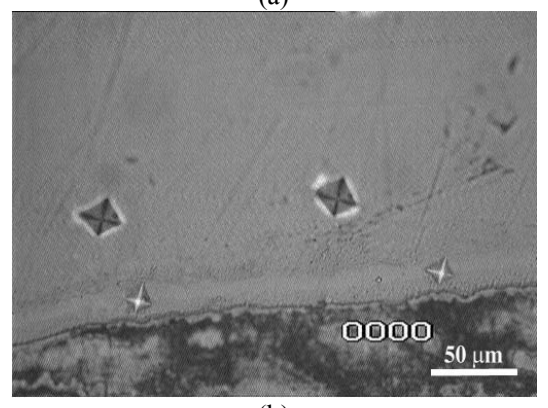

(b)

Fig. 6. (a) Hardness measurement throughout interface at different temperatures; (b) Optical micrograph showing indenter signs near interface.

X-ray diffraction analysis result of the fracture surfaces of the peeling specimens are shown in Figure 7. These analyses are made on titanium side of peeled samples at different temperatures. As can be seen from the figure, the only phases presented in the surface are $\mathrm{Ti}-\mathrm{Cu}$ compounds and there is no evidence of any Ti-Fe intermetallic compounds. This proves that application of $\mathrm{Cu}$ interlayer has an effective role in preventing inter-diffusion of $\mathrm{Ti}$ and $\mathrm{Fe}$ during high temperature roll bonding. Moreover, the presence of $\mathrm{Cu}$ in $\mathrm{XRD}$ results displays that tearing has happened in the thin interface band on titanium side.
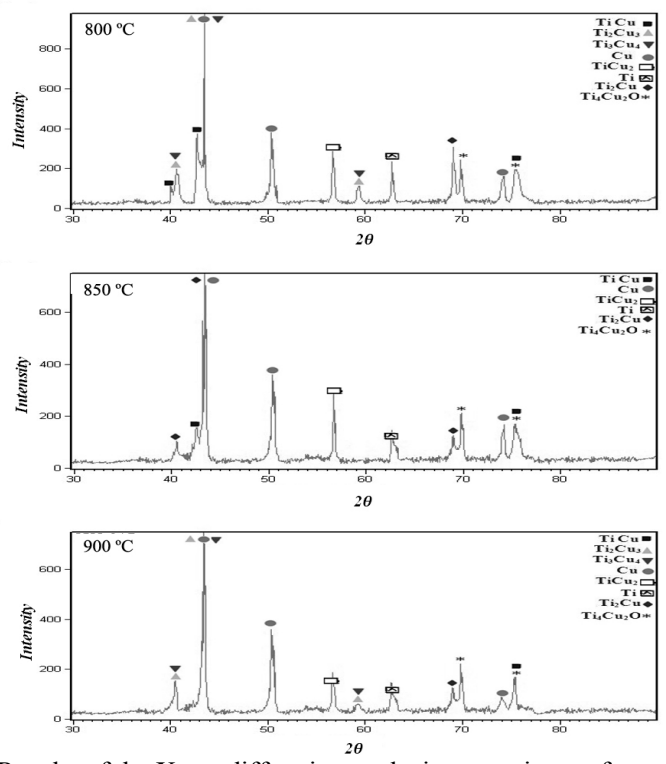

Fig. 7. Results of the X-ray diffraction analysis on tearing surface of peeling samples.

\section{CONCLUSION}

1) Copper interlayer can prevent inter-diffusion between titanium alloy and stainless steel during high temperature roll 
bonding.

2) There is no reaction or diffusion layer at the $\mathrm{Fe}-\mathrm{Cu}$ interface. The reaction layers at the interface of $\mathrm{Cu}$-Ti consist of $\mathrm{TiCu}_{4}, \mathrm{Ti}_{2} \mathrm{Cu}_{3}, \mathrm{Ti}_{3} \mathrm{Cu}_{4}, \mathrm{TiCu}$ and $\mathrm{Ti}_{2} \mathrm{Cu}$ and their mixtures.

3) The intermetallic compounds that formed in $\mathrm{Ti}-\mathrm{Cu}$ mixed layer cause decreasing of average peeling strength.

\section{REFERENCES}

[1] S. N. Polyanskii and V. S. Kolnogorov, "Cladded steel for the oil and gas industries, chemical and Petroleum Engineering," vol. 38, pp. 11-12, 2002.

[2] G. E. Totten, Steel Heat treatment Handbook 2ed, Taylor \& Francis, 2006.

[3] N. Kahramana and B.Gulenc, "Joining of titanium/stainless steel by explosive welding and effect on interface," Materials Processing Technology, vol. 169, pp. 127-133, 2005.

[4] A. Elrefaey and W. Tillmann, "Solid state diffusion bonding of titanium to steel using a copper base alloy as interlayer," Materials Processing Technology, vol. 209, pp. 2746-2752, 2009.

[5] T. Fukuda and Y. Seino, "Bonding strength and microstructure of bonding interface of hot rolled titanium clad steel," Iron and Steel Institute of Japan, vol. 75, pp. 94-101, 1989.

[6] S. Kundu and S. Chatterjee, "Characterization of diffusion bonded joint between titanium and 304 stainless steel using a Ni interlayer," Materials Characterization, vol. 59, pp. 631-637, 2008.

[7] M. K. Lee and J. G. Lee, "Interlayer engineering for dissimilar bonding of titanium to stainless steel," Materials letters, vol. 64, no. 9, pp, 1105-1108, 2010.

[8] A. Elrefaey and W. Tillmann, "Evaluation of Transient Liquid Phase Bonding Between Titanium and Steel," Advanced Engineering Materials, vol. 11, no. 7, pp. 556-560, 2009.

[9] S. Dziallach and W. Bleck, "Roll-Bonded Titanium/ Stainless-Steel Couples, Part1 Diffusion and Interface-Layer Investigation," Advanced Engineering Materials, vol. 11, no. 1-2, pp. 82-87, 2009.

[10] R. Ferro and A. Saccoe, Intermetallic Chemistry, Elsevier, London, 2008.

[11] C. Leyens and M. Peters, Titanium and Titanium Alloy, Wiley-VCH, Germany,2003.

[12] V. N. Moiseyev, Titanium Alloys Russian Aircraft and Aerospace Applications. Taylor \& Francis Group USA: 2006.

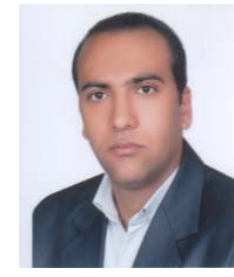

Mohsen Saboktakin, was born in Zarinshahr Iran on August, 1984. He received his B.Sc. in metallurgical engineering from 2003 Islamic Azad university, najafabad branch/Iran in 2007 and the M.Sc. degrees in Identification and selection of engineering materials from Materials science and engineering Department, Islamic Azad University, najafabad Branch, Isfahan, Iran. He has many published articles on Roll bonding of steel to titanium. The present paper has been part of his master thesis

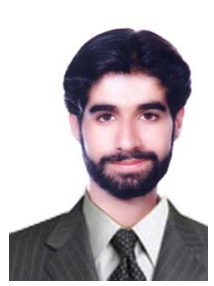

Gholam Reza Razavi, was born in Shahre-kord Iran on August, 1985. He received his B.Sc. in metallurgical engineering from 2004 Islamic Azad university, majlesi branch/Iran in 2007 and his M.Sc. degrees in Identification and selection of engineering materialsfrom Materials science and engineering Department, Islamic Azad University, najafabad Branch, Isfahan, Iran In 2011. He has many published articles on Roll bonding of steel to titanium and thermomechanical processing of High Mn-Steel Such as TWIP Steel. Razavi is presently works at Shahre-Kord University, Iran.

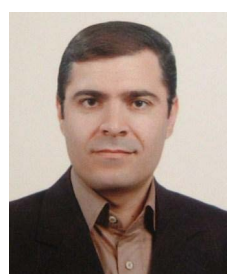

Hossein Monajati, was born in 1973 in Isfahan Iran. $\mathrm{He}$ received his B.Sc. degrees in Mettalurgical Engineering from Najafabad University Isfahan, Iran in 1994, and M.Sc. degree on Identification and selection of materials in 1997 and $\mathrm{PhD}$ degrees in advanced materials in 2005 both from Tarbiat modarres University, Tehran/Iran. He received a full support scholarship from McGill University during his PhD study in 2002-2004 to accomplish a research fellow on thermomechanical processing of Ti alloys at Prof. Jonas labratory. Presently, he is assistant professor in Materials engineering department in Najafabad University, Isfahan/Iran. His main research field is thermomechanical processing of metals and alloys and he has done several industrial projects in collaboration with large steel companies in Iran. 